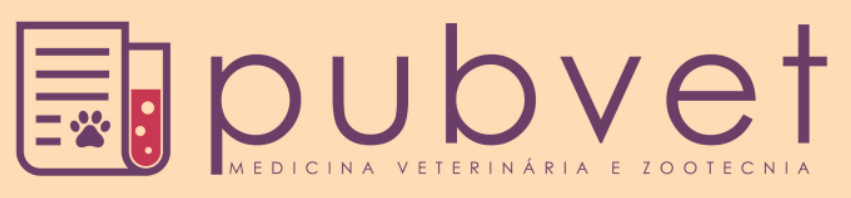

https://doi.org/10.31533/pubvet.v12n8a148.1-5

\title{
Características e preferências de consumo de carne ovina
}

\author{
Juliana Lopes Frias ${ }^{1 *}$, Thiago Belo Ferreira ${ }^{2} \bullet$, Luciano Eduardo Polaquini $^{3} \odot$, Thalita \\ Oliveira Cucki ${ }^{4}$ ๑
}

${ }^{I}$ Médica Veterinária e Nutricionista. Professora da Faculdade de Tecnologia em Hotelaria, Gastronomia e Turismo (HOTEC) São Paulo - SP, Brasil. ${ }^{2} Z$ Zotecnista (Universidade São Marcos). Diretor técnico do Centro de Treinamento Agropecuário BRAVO. Sorocaba-SP, Brasil. ${ }^{3}$ Mestre em Zootecnia (UNESP). Professor da Universidade Anhembi Morumbi. Sócio Diretor da ConsPec Consultoria Pecuária. São Paulo - SP, Brasil. ${ }^{3}$ Doutora em Zootecnia (UNESP). Professora da Universidade Anhembi Morumbi. Sócia Diretora da ConsPec Consultoria Pecuária. São Paulo-SP, Brasil. *Autor para correspondência, E-mail: friasjuliana@hotmail.com

RESUMO. A crescente demanda pela proteína animal é evidente e está sendo cada vez mais valorizada em vários aspectos. Todavia, devemos discutir o mercado da carne de forma ampla à saber e entender o que produzir, como produzir e para quem produzir. Neste contexto, o presente trabalho teve como objetivo identificar informações com relação à preferência de consumo e aquisição de carne ovina de forma a favorecer novas estratégias de comercialização contribuindo com agentes da cadeia produtiva potencialmente demandados por consumidores. Dos entrevistados, $51 \%$ foram mulheres e $49 \%$ homens, sendo que destes $64 \%$ relataram consumir carne ovina pelo menos 1 vez por semana $(31 \%)$. Dos entrevistados que consomem carne ovina (36\%), 25\% relataram ter interesse em consumir manifestando assim curiosidade em experimentar. Quanto às características da carne ovina os entrevistados julgaram importante que a carne apresente sabor, maciez e suculência. No que diz respeito ao teor de gordura $51 \%$ dos entrevistados apontaram a carne marmorizada como sendo a de preferência para consumo. O tipo de corte da carne ovina mais consumido é o pernil (69\%). No entanto, o carré aparece em primeiro lugar como o tipo de corte de preferência para o consumo. A baixa frequência do consumo atual poderia ser explicada pelo fato de que $40 \%$ dos atuais consumidores apresentaram alguma insatisfação relacionada ao preço de venda da carne, e de que $48 \%$ teriam algum tipo de dificuldade em ter acesso ao produto. Foi possível observar um grande potencial de mercado para o consumo de carne ovina. No entanto, alguns aspectos negativos devem ser aprimorados.

Palavras chave: carne; mercado consumidor

\section{Characteristics and preferences of sheep meat consumption}

ABSTRACT. The growing demand for animal protein is evident and is being increasingly valued in several respects. However, we must discuss the meat market broadly to know and understand what to produce, how to produce and who to produce. In this context, the present work aimed to identify information regarding the preference of consumption and purchase of sheep meat in order to favor new marketing strategies contributing with agents of the productive chain potentially demanded by consumers. Of the interviewees, $51 \%$ were women and $49 \%$ men, and of these $64 \%$ reported consuming sheep meat at least once a week $(31 \%)$. Of those interviewed who consume sheep meat (36\%), 25\% reported having an interest in eating, thus expressing curiosity about experimenting. Regarding the characteristics of the sheep meat, the interviewees considered important that the meat shows flavor, softness and succulence. Regarding the fat content, $51 \%$ of the interviewees pointed out the marbled meat as the one of preference for consumption. The type of cut of the sheep meat most consumed is the shank (69\%). However, the cart appears first as the 
cut type of preference for consumption. The low frequency of current consumption could be explained by the fact that $40 \%$ of current consumers showed some dissatisfaction related to the selling price of meat, and that $48 \%$ would have some type of difficulty in gaining access to the product. It was possible to observe a great market potential for the consumption of sheep meat. However, some negatives should be improved.

Keywords: market research, meat

\section{Características e preferencias del consumo de carne ovina}

RESUMEN. La creciente demanda por la proteína animal es evidente y está siendo cada vez más valorada en varios aspectos. Sin embargo, debemos discutir el mercado de la carne de forma amplia a saber y entender qué producir, cómo producir y para quién producir. En este contexto, el presente trabajo tuvo como objetivo identificar informaciones con relación a la preferencia de consumo y adquisición de carne ovina para favorecer nuevas estrategias de comercialización contribuyendo con agentes de la cadena productiva potencialmente demandados por consumidores. De los entrevistados, $51 \%$ fueron mujeres y $49 \%$ hombres, de los cuales $64 \%$ reportaron consumir carne ovina por lo menos 1 vez por semana (31\%). De los entrevistados que consumen carne ovina (36\%), $25 \%$ relataron tener interés en consumir manifestando así curiosidad en experimentar. En cuanto a las características de la carne ovina, los entrevistados juzgaron importante que la carne presente sabor, suavidad y suculencia. En lo que se refiere al contenido de grasa, el $51 \%$ de los entrevistados señalaron la carne marmorizada como la de preferencia para el consumo. El tipo de corte de la carne ovina más consumida es el pernil (69\%). Sin embargo, el t-bone aparece en primer lugar como el tipo de corte de preferencia para el consumo. La baja frecuencia del consumo actual podría ser explicada por el hecho de que el $40 \%$ de los actuales consumidores presentaron alguna insatisfacción relacionada al precio de venta de la carne, y de que el $48 \%$ tendría algún tipo de dificultad en tener acceso al producto. Se observó un gran potencial de mercado para el consumo de carne de ovino. Sin embargo, algunos aspectos negativos deben ser mejorados.

Palabras clave: carne, mercado consumidor

\section{Introdução}

Estimativas da Organização das Nações Unidas para Agricultura e Alimentação ( $\underline{\mathrm{FAO}}$ 2016) apontam que a população mundial possa chegar a 9,3 bilhões de pessoas em meados deste século. Como consequência necessitará aumentar $70 \%$ a produção de alimentos, sendo que o Brasil deverá ser responsável por $40 \%$ deste aumento. Com isso, as cadeias produtoras de proteína animal no país terão papel fundamental em suprir uma parcela desta alimentação nos próximos anos.

A cultura gastronômica do Brasil é sabidamente voltada para carne bovina e de frango, sendo consumidas em várias ocasiões e por todas classes sociais (Eiras et al. 2017; Vital et al. 2018). O mercado consumidor de carne ovina no país é promissor, pois possui atributos que favorecem para o aumento tanto no consumo interno como para exportação (Osório et al. 1995).

As pessoas estão adaptando novos hábitos de consumo, o que favorece o crescimento da demanda pela carne ovina e seus derivados. Para que o consumidor tenha uma boa aceitação deste produto, deve-se procurar produzir um animal que atenda às necessidades de mercado e que apresente padrões de qualidade (Sañudo et al. 2012; Sañudo et al. 2013). Para que essa possa ser competitiva frente às outras espécies, o produtor deve colocar no mercado carne de animais jovens, criados de maneira adequada, para obtenção de carcaças de primeira qualidade, pois o consumidor está cada vez mais exigente e em busca de produtos mais saborosos e saudáveis (Almeida Júnior et al. 2004).

A inexistência de informações fidedignas sobre o consumo de carne ovina contribui como obstáculo ao investimento e expansão desse segmento pecuário. Neste contexto, o presente trabalho teve como objetivo identificar informações com relação à preferência de consumo e aquisição de carne ovina de forma a favorecer novas estratégias de comercialização contribuindo com agentes da cadeia produtiva potencialmente demandados por consumidores. 


\section{Material e Métodos}

Para que o objetivo deste trabalho de caráter exploratório pudesse ser cumprido alguns aspectos metodológicos que foram adotados.

Para a coleta de dados foi elaborado um questionário eletrônico estruturado com questões fechadas de múltipla escolha envolvendo informações pessoais (sexo, idade, escolaridade, profissão, renda familiar e região de moradia); características preferenciais da carne (cor, sabor, maciez, suculência e gordura), frequência e disponibilidade para o consumo, local de aquisição e satisfação com o produto (local e preço). O questionário foi compartilhado em redes sociais de forma aleatória atingindo um total de 398 pessoas no período de junho de 2017 a abril de 2018. Os resultados foram analisados através de técnicas descritivas e gráficos.

\section{Resultados e Discussão}

Dos 398 entrevistados, $51 \%$ foram mulheres e $49 \%$ homens, sendo a maioria residente na região Sudeste $(65 \%)$.

Com relação ao grau de escolaridade $31 \%$ possui curso superior incompleto, outros $31 \%$ somam os que concluíram ou estão em curso do Doutorado, Mestrado ou Pós-Graduação e $29 \%$ possuem curso superior completo.

A composição familiar compreende em sua maioria $(31 \%)$ por três pessoas por família contando com o entrevistado.
Do total de entrevistados, 64\% relataram consumir carne ovina, sendo que destes, $31 \%$ relataram consumir carne ovina pelo menos $1 \mathrm{vez}$ por semana.

Dos $36 \%$ que não consomem carne ovina, $25 \%$ relataram ter interesse em consumir, ou seja, essas pessoas não possuem hábito de consumo, mas manifestaram curiosidade em experimentar, e apenas $11 \%$ relataram não ter interesse em consumir (Figura 1 e 2 ).

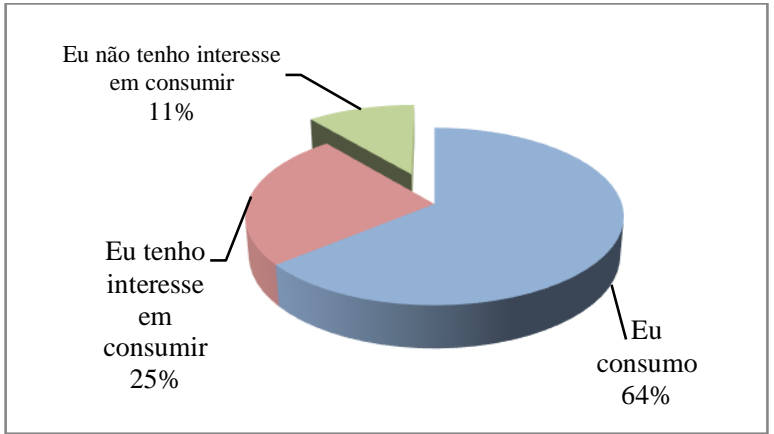

Figura 1. Interesse em consumir carne ovina.

Dentre as pessoas que citaram consumir carne ovina, $60 \%$ têm entre 18 a 35 anos, sendo que destes $57 \%$ possuem renda maior que $\mathrm{R} \$ 4.000,00$ reais por mês. Jesus Junior et al. (2010) corroboram com o presente estudo dizendo que os consumidores de carne ovina das regiões Sul e Sudeste são principalmente das classes econômicas A e B.

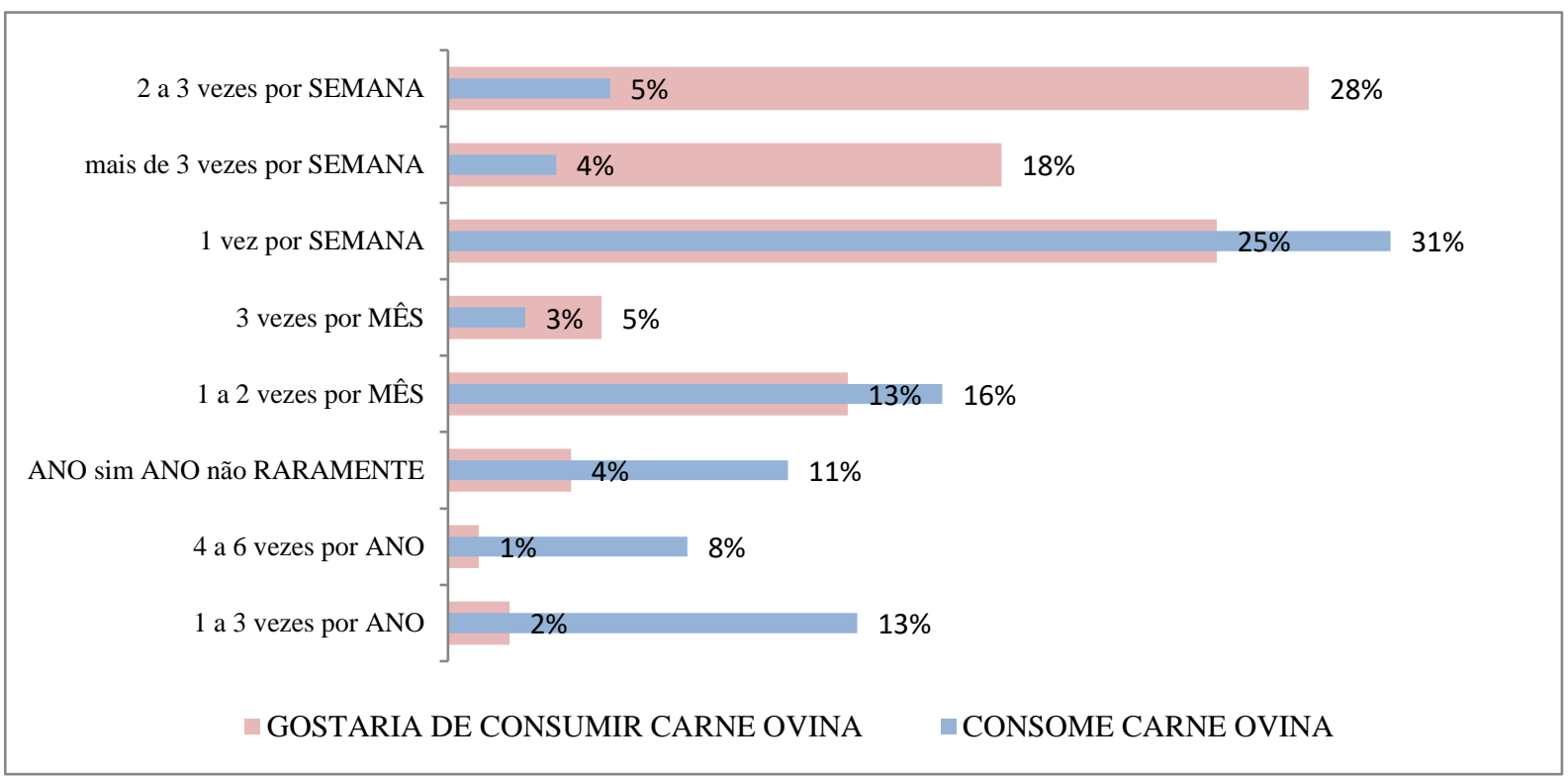

Figura 2. Frequência de consumo versus intenção de consumo da carne ovina. 
Ainda com relação as pessoas que citaram consumir ou ter interesse em consumir carne ovina, $60 \%$ preferem comprar carne ovina fresca/refrigerada, $32 \%$ preferem comprar fresca/refrigerada e/ou congelada e apenas $4 \%$ preferem comprar congelada.

No que diz respeito à preferência de consumo da carne ovina $66 \%$ preferem consumir na forma grelhada ou assada na brasa (churrasco), sendo que $24 \%$ destes preferem a carne "ao ponto". Trabalhos sugerem que o consumo de carne ovina está principalmente associado a datas comemorativas, sendo este elevado consumo observado em festas de fim de ano, churrascos e outras confraternizações (Sorio \& Rasi 2010; Bánkuti et al. 2013).

No presente trabalho dentre as pessoas que citaram consumir carne ovina, 52\% disseram consumir em casa, sendo que este número sobe para $65 \%$ quando questionado o local onde as mesmas gostariam de consumir.

Quanto às características da carne ovina os entrevistados julgam importante que a carne apresente: $87 \%$ citaram sabor, seguidas de $77 \%$ maciez, $67 \%$ suculência, $52 \%$ aparência e $49 \%$ odor. No Rio Grande do Sul, Gonçalvez et al. (2011) desenvolveram um teste de aceitação da carne ovina durante a Expointer, Esteio-RS, no estande da Embrapa, e verificaram que 92\% das pessoas após provar comprariam a carne. Quando solicitado a esses que identificassem qual característica da carne os fez gostar mais, $45 \%$ atribuíram a maciez e $36 \%$ ao sabor.

No que diz respeito ao teor de gordura $51 \%$ dos entrevistados apontaram a carne marmorizada como preferência de consumo, seguidos de $25 \%$ pelo "teor 1 de gordura" e $17 \%$ pelo "teor 2 de gordura" (Figura 3).

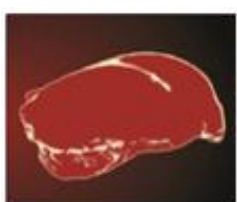

Teor 1 de gordura

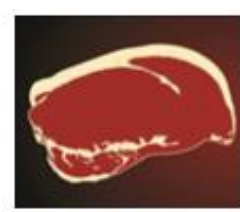

Teor 2 de gordura

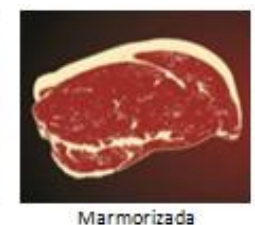

Marmorizada
Figura 3. Ilustração do teor de gordura na carne ovina.

$\mathrm{Na}$ Figura 4 podemos observar que o tipo de corte da carne ovina mais consumido é o pernil (69\%). No entanto, quando questionado sobre a preferência do tipo corte a ser consumido, carré apresenta-se como maioria (67\%).

Com relação ao poder de compra da carne ovina $59 \%$ relataram ser o próprio entrevistado,
$27 \%$ a mãe, $17 \%$ o pai e somando $16 \%$ o cônjuge. Quando questionado o local de compra 58\% disseram comprar em supermercados, seguidos de $25 \%$ em boutique, $20 \%$ em empórios e apenas $3 \%$ em lojas virtuais. Sorio et al. (2008) referem que nas butiques de carne, cujos consumidores são das classes A e B, tinham cortes de carne ovina, demonstrando hábitos de consumo dessas classes sociais. Evidenciou também que uma característica desse segmento varejista é a diversificação de sortimento, que possibilita uma oferta ampla de produtos para atender a uma necessidade específica do consumidor.

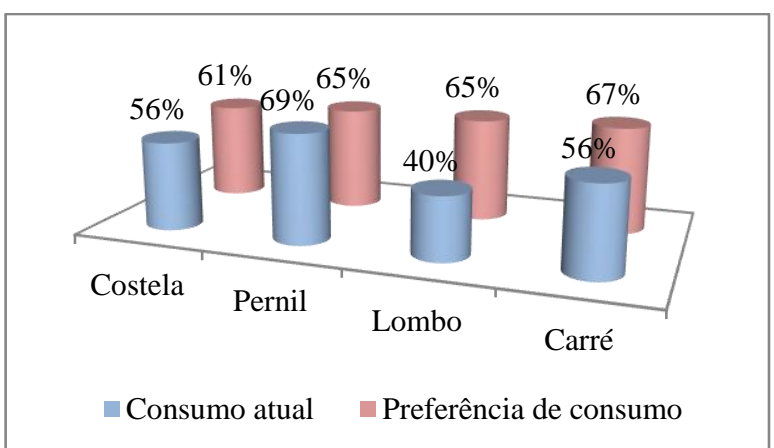

Figura 4. Consumo atual versus Preferência de consumo de acordo com os tipos de cortes para carne ovina.

Bánkuti et al. (2013) em seu estudo ressaltou que o mercado em estudo apresenta algumas restrições do varejo, tais como falhas na disposição do produto ao cliente e promoção ineficaz fazendo com que $69 \%$ dos consumidores adquirissem o produto diretamente do produtor rural. Sorio and Rasi (2010) afirmaram que a carne clandestina representa um problema para o setor, uma vez que há falta de inspeção sanitária e padronização do produto final.

A baixa frequência do consumo atual poderia ser explicada pelo fato de que $40 \%$ dos atuais consumidores apresentam alguma insatisfação com o preço de venda da carne, e de que $48 \%$ teriam algum tipo de dificuldade em ter acesso ao produto, uma vez que o mesmo não seria comercializado em rede varejista próximo a sua residência. (Silva Sobrinho 2001a; Silva Sobrinho 2001b) e Alves et al. (2014) discutem sobre a possibilidade de expansão e aumento na frequência de consumo da carne ovinas desde que aspectos negativos, tais como disponibilidade e preço, sejam contornados.

\section{Conclusão}

Foi possível observar um grande potencial de mercado para o consumo de carne ovina. No 
entanto, alguns aspectos negativos devem ser aprimorados. O preço parece ser o alvo de grande parte desta insatisfação, seguido da dificuldade no acesso ao produto. Desta forma, a cadeia produtiva deverá realizar ajustes no sistema de produção a fim de garantir a oferta do produto, bem como oferecer um produto com qualidade $\mathrm{e}$ uniformidade. Os resultados finais destas pesquisas podem demonstrar aos vários elos da cadeia produtiva que é o consumidor quem manda no jogo. Contudo, alcançar os objetivos estratégicos na cadeia da carne permanece como um grande desafio. Não basta apenas produzir uma carne com características de máxima qualidade, faz-se necessário também informar, educar e ensinar o consumidor a apreciar essas características, já que nem todos os consumidores avaliam os fatores de qualidade da mesma maneira.

\section{Referências bibliográficas}

Almeida Júnior G.A., Costa C., Monteiro A.L.G., Garcia C.A., Munari D.P. \& Neres M.A. 2004. Desempenho, características de carcaça e resultado econômico de cordeiros criados em creep feeding com silagem de grãos úmidos de milho. Revista Brasileira de Zootecnia 33, 1048-59.

Alves L.G.C., Osório J.C.S., Fernandes A.R.M., Ricardo H.A. \& Cunha C.M. 2014. Produção de carne ovina com foco no consumidor. Enciclopédia Biosfera, Centro Científico Conhecer-Goiânia 10, 2399-415.

Bánkuti F.I., Bánkuti S.M.S. \& Macedo F.A.F. 2013. A informalidade em sistemas agroindustriais: um estudo exploratório dos hábitos de consumo de carne ovina na cidade de Maringá, Estado do Paraná. Informações Econômicas 43, 5-17.

Eiras C.E., Guerrero A., Valero M.V., Pardo J.A., Ornaghi M.G., Rivaroli D.C., Sañudo C. \& Prado I.N. 2017. Effects of cottonseed hulls levels in the diet and aging time on visual and sensory meat acceptability from young bulls finished in feedlot. animal 11, 529-37.

FAO 2016. Statistical Yearbook. Food and Agriculture Organization of the United Nations, Rome, Italy.

Gonçalvez M.S., Arnoni R.K., Esteves R.M.G., Kessler J.D., Lemes J.S., Martins L., Oliveira R., M., Pinheiro L., Osório M.T.M., Osório J.C.S., Ferreira O.G., Borba M.F.S., Trindade
J.P.P. \& Gonzaga S.S. 2011. Acceptance of sheep and goat meat from Alto Camaquã. Revista Argentina de Producción Animal 1, 113-.

Jesus Junior C., Rodrigues L.S. \& Moraes V.E.G. 2010. Ovinocaprinocultura de corte: a convivência dos extremos. BNDS - Setorial 31, 281-320.

Osório J.C.S., Sierra I., Sañudo C., Maria G. \& Osório M.T. 1995. Estudio comparativo de la calidad de la canal en el tipo" ternasco" según procedencia. Current Agricultural Science and Technology 1, 145-50.

Sañudo C., Campo M.M., Muela E., Olleta C.J.L., Delfa B.R., Jiménez B.R., J. A.A.M., Horcada I.A., Oliveira I. \& Cilla I. 2012. Carcass characteristics and instrumental meat quality of suckling kids and lambs. Spanish Journal of Agricultural Research 10, 690-700.

Sañudo C., Muela E. \& Campo M.M. 2013. Key factors involved in lamb quality from farm to fork in europe. Journal of integrative agriculture 12, 1919-30.

Silva Sobrinho A. 2001 a. Aspectos quantitativos e qualitativos da produção de carne ovina. Reunião Anual da Sociedade Brasileira de Zootecnia 38, 425-46.

Silva Sobrinho A.G. 2001b. Criação de ovinos. Funep, Jaboticabal.

Sorio A., Fagundes M.B.B. \& Leite L.R.C. 2008. Oferta de carne ovina no varejo de Campo Grande (MS). Agrarian 1, 145-56.

Sorio A. \& Rasi L. 2010. Ovinocultura e abate clandestino: um problema fiscal ou uma solução de mercado? Revista de Política Agrícola 19, 71-83.

Vital A.C.P., Guerrero A., Kempinski E.M.B.C., Monteschio J.O., Sary C., Ramos T.R., Campo M.M. \& Prado I.N. 2018. Consumer profile and acceptability of cooked beef steks with edible and active coating containing oregano and rosemary essential oils. Meat Science 143, 153-8.

Recebido: 23 Mai., 2018

Aprovado: 19 Jun. 2018

Publicado: 9 Ago. 2018

Licenciamento: Este artigo é publicado na modalidade Acesso Aberto sob a licença Creative Commons Atribuição 4.0 (CC-BY 4.0), a qual permite uso irrestrito, distribuição, reprodução em qualquer meio, desde que o autor e a fonte sejam devidamente creditados. 